Leading article

\title{
Bone disease after liver transplantation
}

It is well known that bone problems occur in patients with chronic liver disease, both cholestatic and noncholestatic. ${ }^{1-3}$ Bone disorders associated with chronic liver disease may be classified on a histological basis into osteomalacia, a reduction in mineralisation of bone matrix and osteoporosis, a reduction in total bone mass but with normal mineralisation. Osteomalacia in patients with liver disease occurs particularly with cholestatic disease, is associated with vitamin D deficiency, and responds to administration of vitamin D in any form. ${ }^{4}$ The vitamin D deficiency is probably multifactorial. It might be anticipated that hydroxylation in the liver would be deficient but this seems rarely to be the case. ${ }^{6}$ Malabsorption of vitamin $\mathrm{D}$, especially in cholestatic disease, is a possible factor. ${ }^{7}$ Lack of exposure to sunlight may be a factor in severely ill patients. ${ }^{9}$ Abnormal metabolism of vitamin D or its metabolites seems to play a part in hepatic osteomalacia. ${ }^{7}$ Recent attention has centred much more on osteoporosis because osteomalacia is a generalised disease and is readily diagnosed and can be successfully treated.

The pathogenesis of osteoporosis in liver disease is not understood but many factors have been invoked. ${ }^{10}$ Hypogonadism and cirrhosis ${ }^{11}$ are independent predictors of osteoporosis. Indeed hypogonadism was strongly associated with osteoporosis in patients with idiopathic haemochromatosis. ${ }^{12}$ Chronic intestinal malabsorption of calcium may induce hepatic osteoporosis. ${ }^{13} 14$ Inactivity, and especially bed rest as a consequence of severe liver disease also contribute to osteoporosis. Alcohol ingestion is also a factor in osteoporosis. ${ }^{15}{ }^{16}$ Steroid treatment is a well authenticated cause of osteoporosis. ${ }^{17}$ Corticosteroid therapy reduces bone mineral density in patients with autoimmune chronic active hepatitis ${ }^{1819}$ and primary biliary cirrhosis. ${ }^{2021}$

Studies in mixed populations with chronic liver disease $^{1122}$ show reduced bone mineral density in $29-39 \%$ of patients and the prevalence rate of spinal and peripheral fractures is twice as high in patients with chronic liver disease as in controls. ${ }^{11}$ Primary biliary cirrhosis is a paradigm of chronic cholestasis, can be diagnosed early in its course, and thus can be studied sequentially and is the condition par excellence for which liver transplantation is used successfully. Studies of the bones in the early stages of the disease show essentially normal findings, ${ }^{23}$ and show that the effects of one year of steroid use cause increased bone loss. ${ }^{20}$ Cross sectional surveys show poor correlation of reduced bone mineral density with duration of disease, liver function or previous steroid treatment. ${ }^{24}$ None the less, osteoporosis is more prevalent in postmenopausal women with primary biliary cirhossis, and in some studies in those with a prolonged duration of disease. ${ }^{14}$ Longitudinal measurements of bone mineral density improve with vitamin D and calcium supplements either alone ${ }^{25}$ or with adjuvant calcitonin therapy ${ }^{26}$ presumably by reducing bone resorption. The principal mechanism for hepatic osteoporosis is probably reduced bone formation due to impaired osteoblast function, ${ }^{27} 28$ although increased bone resorption may also contribute. ${ }^{27}$
Thus, some patients undergoing liver transplantation have marked pre-existing bone disease, which may be accentuated by factors, such as prolonged bed rest and immobilisation. ${ }^{29}$ Immunosuppression, particularly corticosteroid therapy, also contributes to a reduction in bone mineral density. ${ }^{30}$ Furthermore, both cyclosporine $\mathrm{A}^{31-33}$ and tacrolimus ${ }^{33}$ increase bone resorption in animal models leading to a loss of trabecular bone. Cardiac transplant patients have cyclosporine associated osteoporosis. ${ }^{34}{ }^{35}$ However, good graft function after liver transplantation should perhaps, overcome the osteoporotic effects of the underlying liver disease. Unfortunately, the initial studies of bone disease after liver transplantation were not encouraging. Haagsma and colleagues, ${ }^{36} \mathrm{dem}-$ onstrated vertebral collapse in more than one in three patients despite comparatively minor bone disease preoperatively and treatment with a vitamin D analogue and supplementary calcium postoperatively. This contrasts with kidney transplantation, which is sometimes followed by avascular bone necrosis principally of the femoral head, but infrequently by generalised osteoporosis. Secondary hyperparathyroidism in chronic renal disease after transplantation may explain this difference. However, secondary hyperparathyroidism is also associated with chronic liver disease ${ }^{37}$ Haagsma $e t a l^{36}$ suggested that the pre-existing bone disease in liver transplant recipients was a major factor in the development of bone disease but in their patients another major factor may have been the postoperative dose of corticosteroid immunosuppression as they were treated with $200 \mathrm{mg}$ of prednisolone/day reducing to $40 \mathrm{mg} /$ day after one month and $20 \mathrm{mg} /$ day at one year - high doses of corticosteroids compared with current regimens.

Porayko and coworkers ${ }^{38}$ showed an early fall in lumbar spine bone mineral density three months after transplantation, particularly in patients with cholestatic liver disease (primary biliary cirrhosis or primary sclerosing cholangitis) because their values before transplantation were much lower than those of patients with chronic active hepatitis or other liver diseases. After three months, however, bone mineral density in cholestatic liver disease improved whereas that in the other liver diseases continued to deteriorate for up to two years. They also noted avascular bone necrosis in patients with cholestatic liver disease undergoing liver transplantation. Further analysis ${ }^{39}$ showed that, in women with primary biliary cirrhosis, lumbar spine bone mineral density was inversely related to the severity of liver disease and the mean rate of bone loss was double that in normal women. This study confirmed the loss of bone mineral density in the lumbar spine in the first three months after liver transplantation with $65 \%$ of patients sustaining atraumatic fractures. Perhaps related osteoporosis and bone fracture may have been secondary to the high dose corticosteroid used in the immunosuppressive regimen. When the dose of prednisolone was reduced to $10 \mathrm{mg} /$ day after six months, there was a gradual reversal of bone deficit and bone mineral density had recovered to the pre-operative level by about 12 months 
and above the pre-operative level by two years. Furthermore, osteoporosis in this group may have been exaggerated because $38 \%$ of patients had amenorrhoea secondary to natural menopause or oophorectomy. An early fall in bone mineral density within three to six months, which thereafter remained stable in most patients up to 36 months, after liver transplantation was confirmed by Arnold and colleagues. ${ }^{40}$ They also found a high rate (31\%) of atraumatic bone fracture, mainly in the first 12 months after transplantation.

Argao et al considered the role of vitamin D supplementation in the recovery of post-transplant bone disease. $^{41}$ All their infants and children with chronic cholestasis had subnormal bone mineral content before transplantation. Bone mineral content increased in all patients after transplantation. There was an initial decrease in bone mineral content up to about three or four months after operation in half of the patients with a corresponding fall in serum vitamin $D$ values, suggesting a role for vitamin $\mathrm{D}$ supplementation. There was no correlation in individual patients between the change in serum vitamin $\mathrm{D}$ level and the change in bone mineral density.

When patients before and one year after liver transplantation ${ }^{42}$ are compared there is a high $(30 \%)$ incidence of vertebral fractures but no difference in bone mass. Longitudinal studies, however, showed significant differences with clear cut losses in spinal bone mineral density and total body bone mineral content. This highlights a potential problem in cross sectional studies where the assumption is made that comparisons are valid. In practice the type of liver disease, the stage of liver disease, the management of transplantation, and the post-transplant drug treatment may vary. This could account for the lack of correlation between the reduction in bone mineral density and factors such as duration and dose of corticosteroid immunosuppression after transplantation found in a cross sectional study of 71 patients from Spain. ${ }^{43}$

Studies from Spain ${ }^{44}$ suggested the problems of bone loss after transplantation were less severe than those reported by others. ${ }^{36} 394042$ In 82 patients undergoing liver transplantation $41 \%$ were osteoporotic as defined by a bone mineral density of more than 2 SD below the mean for normal matched subjects. Although measurements of serum bone markers suggested increased bone loss and high bone turnover, there was no reduction in bone mineral density, nor any clinical or radiological evidence of vertebral collapse or hip fractures or radiological osteonecrosis in the hip after transplantation. This impression of fewer problems with bone disease after liver transplantation in recent years accords with our own studies. ${ }^{45}$ In an earlier communication we concluded that, after orthotopic liver transplantation, patients are at an increased risk for the development of severe osteoporosis ${ }^{45}$ and found a significant detriment in spinal bone mineral density not only in patients with cholestatic liver disease, but also in those with chronic active hepatitis and cryptogenic cirrhosis prior to transplantation. Patients after transplantation had the most severe osteoporosis of all. However, in our more recent studies ${ }^{46}$ we found that severe osteoporosis before liver transplantation was uncommon. Furthermore, in contrast with other studies after transplantation, there was only a marginal fall in femoral neck bone mineral density in the short-term, and in the longterm bone mineral density improved after transplantation.

The pathogenesis of reduced bone mineral density after transplantation is unclear. Bone histomorphometric studies before, and three months after, transplantation suggested increased bone formation by osteoblasts. ${ }^{47}$ This was associated with a rise in serum osteocalcin, a vitamin
$\mathrm{K}$ dependent protein, synthesised by osteoblasts and distinct from collagen, which is regarded as an index of bone turnover. However the spinal bone mineral density decreased in the first three months after liver transplantation with no further decrease at 12 months. Because histomorphometric studies were not performed during the initial three months after transplantation it is unclear whether increased bone resorption or reduced bone formation was responsible for bone loss. Bone loss was related to the duration of hospital stay (and thus immobility), with no correlation with the dose of corticosteroids or cyclosporine. The increase in osteocalcin after transplantation has been reported in patients with primary biliary cirrhosis. ${ }^{48}$ However, there was no clear relation between osteocalcin and the time since transplantation. The authors speculated that the rise in osteocalcin may have been secondary to cyclosporine treatment. The role of osteocalcin in the pathogenesis of bone disease after transplantation is further complicated by the effect of vitamin K deficiency on osteocalcin levels. ${ }^{49}$

What lessons can be learned from these studies of bone disease after liver transplantation? There is abundant evidence that chronic liver disease, particularly of the cholestatic variety, is associated with a diminution in bone mineral density and the risk of atraumatic fractures. This problem is related both to the type of liver disease and its severity. In some circumstances in the few months after liver transplantation bone disease can deteriorate with an increase in the prevalence of atraumatic fractures. This is not a universal finding and is probably becoming less of a problem. A number of factors are involved. Firstly, the severity of disease at the time of referral to a transplant centre may be less now than it was even a few years ago. Patients may be transplanted at an earlier stage when the liver disease and bone disease is less severe. Changing indications for transplantations, for example lethargy, pruritus or portal hypertension, when the parenchymal liver disease is less severe may all play a part. In this context it is notable that there is a well defined subgroup of patients with primary biliary cirrhosis in whom portal hypertension is the dominant feature, indications of the severity of hepatocellular parenchymal disease being less marked. ${ }^{50}$ Finally postoperative regimens are changing. Patients now spend much less time in intensive care and as inpatients and postoperative mobilisation is more rapid. The immunosuppressive regimens have changed with less reliance on corticosteroids and this may well be a further factor in minimising bone disease.

Precise details of studies must be scrutinised carefully to ensure that only justified conclusions are drawn and the problem of bone disease has highlighted the defects in cross sectional studies in relation to an evolving form of treatment such as liver transplantation.

M S LOSOWSKY S H HUSSAINI Academic Division of Medicine, Level 7, Clinical Science Building, St fames's University Hospital, Leeds LS9 $7 T F$

1 Atkinson M, Nordin BEC, Sherlock S. Malabsorption and bone disease in prolonged obstructive jaundice. $Q \mathcal{F}$ Med 1956; 25: 299-312

2 Summerskill WHJ, Kelly PJ. Osteoporosis with fractures in anicteric cirrhosis: observations supplemented by microradiographic evaluation of bone. Proc Mayo Clin 1963; 38: 162-74.

3 Paterson CR, Losowsky MS. The bones in chronic liver disease. Scand $\mathcal{F}$ Gastroenterol 1967; 2: 293-300.

4 Reed JS, Meredith SC, Nemchausky BA, Rosenberg IH, Boyer JL. Bone disease in primary biliary cirrhosis: reversal of osteomalacia with oral 25-hydroxyvitamin D. Gastroenterology 1980; 78: 512-7.

5 Dibble JB, Sheridan P, Hampshire R, Hardy GJ, Losowsky MS. Osteomalacia, vitamin $D$ deficiency and cholestasis in chronic liver disease. $Q \mathcal{M}$ Med 1982; 201: 89-103

6 Hepner G, Roginsky M, Moo HF. Abnormal vitamin D metabolism in patients with cirrhosis. Am $\mathcal{F}$ Dig Dis 1976; 21 : 527-32. 
7 Krawitt EL, Grundman MJ, Mawer EB. Absorbtion, hydroxylation and excretion of vitamin D3 in primary biliary cirrhosis. Lancet 1977; ii: excretion

8 Compston JE, Thompson RP. Intestinal absorption of 25-hydroxyvitamin $D$ and osteomalacia in primary biliary cirrhosis. Lancet 1977; i: 721-4

9 Davies M, Mawer EB, Klass HJ, Lumb GA, Berry JL, Warnes TW. Vitamin $D$ deficiency, osteomalacia, and primary biliary cirrhosis: response to orally administered vitamin D3. Dig Dis Sci 1983; 28: 145-53.

10 McCaughan GW, Feller RB. Osteoporosis in chronic liver disease: pathogenesis, risk factors, and management. Dig Dis 1994; 12: 223-31.

11 Diamond T, Stiel D, Lunzer M, Wilkinson M, Roche J, Posen S. Osteoporosis and skeletal fractures in chronic liver disease. Gut 1990; 31: 82-7.

12 Diamond T, Stiel D, Posen S. Osteoporosis in haemochromatosis: iron excess, gonadal deficiency, or other factors? Ann Intern Med 1989; 110: 430-6.

13 Matloff DS, Kaplan MM, Neer RM, Goldberg MJ, Bitman W, Wolfe HJ. Osteoporosis in primary biliary cirrhosis: effects of 25 -hydroxy vitamin D3 treatment. Gastroenterology 1982; 83: 97-102

14 Guañabens N, Parés A, Mariñoso L, Brancós A, Piera C, Serrano S, et al. Factors influencing the development of metabolic bone disease in primary biliary cirrhosis. Am f Gastroenterol 1990; 85: 1356-62.

15 Diamond T, Stiel D, Lunzer M, Wilkinson M, Posen S. Ethanol reduces bone formation and may cause osteoporosis. Am $\mathcal{Y} M e d$ 1989; 86: 282-8.

16 Rico H. Alcohol and bone disease. Alcohol Alcohol 1990; 25: 345-52.

17 Reid IR. Pathogenesis and treatment of steroid osteoporosis. Clin Endocrinol 1989; 30: 83-103.

18 Stellon AJ, Davies A, Compston J, Williams R. Bone loss in autoimmune chronic active hepatitis on maintenance corticosteroid therapy. chronic active hepatitis on main
Gastroenterology 1985; 89: 1078-83.

19 Stellon AJ, Webb A, Compston JE. Bone histomorphometry and structure in corticosteroid treated chronic active hepatitis. Gut 1988; 29: 378-84.

20 Mitchison HC, Bassendine MF, Malcolm AJ, Watson AJ, Record CO, James OFW. A pilot, double-blind, controlled 1-year trial of prednisolone treatment in primary biliary cirrhosis: hepatic improvement but greater bone loss. Hepatology 1989; 10: 420-9.

21 van Berkum FNR, Beukers R, Birkenhäger JC, Kooij PPM, Schalm SW, Pols HAP. Bone mass in women with primary biliary cirrhosis: The relation with histological stage and use of glucocorticoids. Gastroenterology 1990; 99: 1134-9.

22 Bonkovsky HL, Hawkins M, Steinberg $\mathrm{K}$, Hersh T, Galambos JT, Henderson JM, et al. Prevalence and prediction of osteopenia in chronic Henderson JM, et al. Prevalence and predict

23 Mitchison HC, Malcolm AJ, Bassendine MF, James OFW. Metabolic bone disease in primary biliary cirrhosis at presentation. Gastroenterology 1988; 94: 463-70.

24 Almdal T, Schaadt O, Vesterdal Jørgensen J, Lindgreen P, Ranek L. Vitamin $\mathrm{D}$, parathyroid hormone, and bone mineral content of lumbar spine and femur in primary biliary cirrhosis. $\mathcal{F}$ Int Med 1989; 225: 207-13.

25 Epstein O, Kato Y, Dick R, Sherlock S. Vitamin D, hydroxyapatite, and calcium gluconate in treatment of cortical bone thinning in postmenopausal women with primary biliary cirrhosis. Am $f$ Clin Nut 1982; 36: 426-30.

26 Floreani A, Chiaramonte M, Giannini S, Malvasi L, Lodetti MG, Castrignano $\mathrm{R}$, et al. Longitudinal study on osteodystrophy in primary biliary cirrhosis (PBC) and a pilot study on calcitonin treatment. $\mathcal{f}$ Hepatol 1991; 12: 217-23.

27 Stellon AJ, Webb A, Compston J, Williams R. Low bone turnover state in primary biliary cirrhosis. Hepatology 1987; 7: 137-42.

28 Diamond TH, Stiel D, Lunzer M, McDowall D, Eckstein RP, Posen S. Hepatic osteodystrophy. Static and dynamic bone histomorphometry and serum bone Gla-protein in 80 patients with chronic liver disease. Gastroenterology 1989; 96: 213-21.

29 Hulley SB, Vogel JM, Donaldson CL, Bayers JH, Friedman RJ, Rosen SN. The effect of supplemental oral phosphate on bone mineral changes during prolonged bed rest. $\mathcal{f}$ Clin Invest 1971 ; 50: 2506-18.
30 Lukert BP, Raisz LG. Glucocorticoid induced osteoporosis:pathogenesis and management. Ann Intern Med 1990; 112: 352-64.

31 Movsowitz C, Epstein S, Fallon M, Ismail F, Thomas S. Cyclosporin-A in vivo produces severe osteopenia in the rat: effect of dose and duration of administration. Endocrinology 1988; 123: 2571-7.

32 Stewart PJ, Stern PH. Inhibition of parathyroid hormone and interleukin 1-stimulated bone resorption by cyclosporine A but not cyclosporine $\mathrm{H}$ or F. Transplant Proc 1988; 20 (suppl 3): 989-92.

33 Cvetkovic M, Mann GN, Romero DF, Liang XG, Ma Y, Jee WSS, et al. The deleterious effects of long-term cyclosporine A, Cyclosporine $G$, and FK506 on bone mineral metabolism in vivo. Transplant Proc 1994; 57: 1231-7.

34 Rich GM, Mudge GH, Laffel GL, LeBoff MS. Cyclosporine A and prednisolone associated osteoporosis in heart transplant recipients. $\mathcal{F}$

35 Shane E, Rivas MC, Silverberg SI, Kim TS, Staron RB, Bilezikian IP. Osteoporosis after cardiac transplantation. Am $\mathcal{f}$ Med 1993; 94: 257-64.

36 Haagsma EB, Thijn CJ, Post JG, Slooff MJH, Gips CH. Bone disease after orthotopic liver transplantation. $\mathcal{f}$ Hepatol 1988; 6: 94-100.

37 Dibble JB, Sheridan P, Hampshire R, Hardy GJ, Losowsky MS. Evidence for secondary hyperparathyroidism in the osteomalacia associated with chronic liver disease. Clin Endocrinol 1981; 15: 373-83.

38 Porayko MK, Wiesner RH, Hay JE, Krom RA, Dickson ER, Beaver S, et al. Bone disease in liver transplant recipients: incidence, timing, and risk factors. Transplant Proc 1991; 23: 1462-5.

39 Eastell R, Dickson ER, Hodgson SF, Wiesner RH, Porayko MK, Wahner HW, et al. Rates of vertebral bone loss before and after liver transplantation in women with primary biliary cirrhosis. Hepatology 1991; 14: 296-300.

40 Arnold JC, Hauser D, Ziegler R, Kommerell B, Otto G, Theilmann L, et al. Bone disease after transplantation. Transplant Proc 1992; 24:

41 Argao EA, Balistreri WF, Hollis BW, Ryckman FC, Heubi JE. Effect of orthotopic liver transplantation on bone mineral content and serum vitamin D metabolites in infants and children with chronic cholestasis. Hepatology 1994; 20: 598-603.

42 Meys E, Fontanges E, Fourcade N, Thomasson A, Pouyet M, Delmas PD. Bone loss after orthotopic liver transplantation. Am f Med 1994; 97: 445-50.

43 Lopez MB, Gonzalez Pinto I, Hawkins F, Valero MA, Leon M, Loinaz C, et al. Effect of liver transplantation and immunosuppressive treatment on et al. Effect of liver transplantation and immunosuppressive

44 Hawkins FG, Leon M, Lopez MB, Valero MA, Larrodera L, Garcia-Garcia $\mathrm{I}$, et al. Bone loss and turnover in patients with liver transplantation. Hepatogastroenterology 1994; 41: 158-61.

45 Bramley P, Oldroyd B, Stewart SP, Pitt E, Simpson M, Losowsky M, et al. The magnitude of osteopenia in chronic liver disease and following liver transplantation. In: Ring EFJ, ed. Current research in osteoporosis and bone mineral measurement II: 1992. British Institute of Radiology 1992: 73-4.

46 Hussaini SH, Stewart SP, Roman F, Oldroyd B, Bramley P, Simpson M, et al. Osteopenia after liver transplantation: an overestimated risk? Gut 1995; 36(S1): A20.

47 McDonald JA, Dunstan CR, Dilworth P, Sherbon K, Ross Sheil AG, Evans RA et al. Bone loss after liver transplantation. Hepatology 1991; 14: 613-9.

48 Watson RGP, Coulton L, Kanis JA, Lombard M, Williams R, Neuberger $\mathrm{J}$, et al. Circulating osteocalcin in primary biliary cirrhosis following liver transplantation and during treatment with ciclosporin. $\mathcal{F}$ Hepatol 1990; 11 : 354-8.

49 Knapen MH, Hamulyak K, Vermeer C. The effect of vitamin K supplementation on circulating osteocalcin (bone Gla protein) and urinary calcium excretion. Ann Intern Med 1989; 111: 1001-5.

50 Thornton JR, Triger DR, Losowsky MS. Variceal bleeding is associated with reduced risk of severe cholestasis in primary biliary cirrhosis. $Q \mathcal{F} \mathrm{Med}$ 1989; 71: 467-71. 